\title{
Synergistic Effect in an Au-Ag Alloy Nanocatalyst: CO Oxidation
}

\author{
Jun-Hong Liu, ${ }^{\dagger}$ Ai-Qin Wang, ${ }^{\dagger}$ Yu-Shan Chi, ${ }^{\dagger}$ Hong-Ping Lin,,${ }^{\ddagger}$ and Chung-Yuan Mou ${ }^{*}, \dagger$ \\ Department of Chemistry, National Taiwan University, Taipei 106, Taiwan, and Department of Chemistry, \\ National Cheng Kung University, Tainan 701, Taiwan
}

Received: November 5, 2004; In Final Form: November 24, 2004

\begin{abstract}
$\mathrm{Au}-\mathrm{Ag}$ alloy nanoparticles supported on mesoporous aluminosilicate have been prepared by one-pot synthesis using hexadecyltrimethylammonium bromide $(\mathrm{CTAB})$ both as a stabilizing agent for nanoparticles and as a template for the formation of mesoporous structure. The formation of $\mathrm{Au}-\mathrm{Ag}$ alloy nanoparticles was confirmed by X-ray diffraction (XRD), ultraviolet-visible (UV-vis) spectroscopy, and transmission electron microscopy (TEM). Although the $\mathrm{Au}-\mathrm{Ag}$ alloy nanoparticles have a larger particle size than the monometallic gold particles, they exhibited exceptionally high activity in catalysis for low-temperature $\mathrm{CO}$ oxidation. Even at a low temperature of $250 \mathrm{~K}$, the reaction rate can reach $8.7 \times 10^{-6} \mathrm{~mol} \cdot \mathrm{g}_{\text {cat. }}{ }^{-1} \cdot \mathrm{s}^{-1}$ at an $\mathrm{Au} / \mathrm{Ag}$ molar ratio of 3/1. While neither monometallic Au@MCM-41 nor Ag@MCM-41 shows activity at this temperature, the $\mathrm{Au}-\mathrm{Ag}$ alloy system shows a strongly synergistic effect in high catalytic activity. In this alloy system, the size effect is no longer a critical factor, whereas $\mathrm{Ag}$ is believed to play a key role in the activation of oxygen.
\end{abstract}

Worldwide attention has been aroused by the discovery of Haruta and co-workers concerning the catalysis of gold nanoparticles in a class of oxygen-transfer reactions near ambient temperature. ${ }^{1}$ In particular, the oxidation of carbon monoxide has attracted a lot of interest, and the catalytic activity has been found to be sensitive to the size of the gold nanoparticles, the nature of the support, and the preparation methods. ${ }^{2}$

Central to the problem of $\mathrm{CO}$ oxidation is the activation of oxygen molecules. ${ }^{3}$ While gold nanoparticles adsorb $\mathrm{CO}$ molecules well, they do not strongly adsorb and activate oxygen molecules. ${ }^{4,5}$ Thus, the oxide support often plays an important role in the activation of oxygen. It has been proposed that the active sites are at the gold/oxide contact peripherals. ${ }^{3,6}$ In fact, almost all the active gold catalysts reported so far are a combination of an active support $\left(\mathrm{TiO}_{2}, \mathrm{Fe}_{2} \mathrm{O}_{3}\right.$, etc. $)$ and a small size for gold particles $(\sim 3 \mathrm{~nm})$.

An alternative way to obtain an active catalyst for $\mathrm{CO}$ oxidation is to make gold alloy nanoparticles with a metal of stronger reduction tendency. In this case, the electron transfer to oxygen would be stronger, while one can still have good $\mathrm{CO}$ adsorption. Previously, Häkkinen et al. found $\mathrm{Au}_{n} \mathrm{Sr}$ clusters are more active in catalyzing $\mathrm{CO}$ oxidation. ${ }^{7}$ However, their method of the soft-landing of mass-selected cluster ions onto $\mathrm{MgO}$ cannot be used to generate a large amount of catalyst. Guczi et al. ${ }^{8}$ investigated $\mathrm{CO}$ oxidation catalyzed by AuPd bimetallic nanoparticles on $\mathrm{SiO}_{2}$, but no synergistic effect was found when compared to the activity of monometallic catalyst. This may be because $\mathrm{Pd}$ adsorbs $\mathrm{O}_{2}$ so strongly that the role of $\mathrm{Au}$ is weakened.

* Corresponding author. E-mail: cymou@ntu.edu.tw. Fax: +886-22366-0954.

† National Taiwan University.

$\doteqdot$ National Cheng Kung University.

10.1021/jp044938g CCC: $\$ 30.25$
Very recently, Iizuka et al. ${ }^{9}$ found that there is some impurity of silver in gold nanoparticles and the effect of the impurity is to enhance $\mathrm{CO}$ oxidation. The degree of enhancement is strongly correlated with the surface silver content. However, the silver as an impurity in Au nanoparticles cannot be controlled synthetically. In this paper, we report $\mathrm{Au}-\mathrm{Ag}$ alloy nanoparticles deposited on inert support MCM as a catalyst for $\mathrm{CO}$ oxidation, and a strongly synergistic effect of catalytic activity is found for the first time.

$\mathrm{The} \mathrm{Au}-\mathrm{Ag}$ alloy nanoparticles deposited on a mesoporous aluminosilicate support (denoted as $\mathrm{Au}-\mathrm{Ag} @ \mathrm{MCM}$ ) were synthesized by a one-pot approach similar to that described earlier. ${ }^{10}$ We first make $\mathrm{Au}-\mathrm{Ag}$ alloy nanoparticles protected by hexadecyltrimethylammonium bromide (CTAB) in solution. Then, the colloid solution is directly used in a sol-gel synthesis of MCM-41. As a consequence, the alloy nanoparticles are uniformly dispersed in the MCM-41 product. Briefly, a proper amount of $\mathrm{HAuCl}_{4}$ (Aldrich) and $\mathrm{AgNO}_{3}$ (AcrÔs) was added into an aqueous solution of quaternary ammonium surfactant CTAB (AcrÔs) to form a clear yellow-colored solution. Then, $\mathrm{NaBH}_{4}$ solution was added and a dark-red solution was formed. After that, the $\mathrm{Au}-\mathrm{Au}$ alloy nanoparticle solution was directly poured into a sodium aluminosilicate solution and a red-colored precipitate formed immediately. The gel solution was then transferred to an autoclave to undergo hydrothermal reaction at $100{ }^{\circ} \mathrm{C}$ for $6 \mathrm{~h}$. Overall, the molar ratio in the aluminosilicate gel is $1.0 \mathrm{SiO}_{2} / 0.027 \mathrm{NaAlO}_{2} / 0.18 \mathrm{CTAB} / 493 \mathrm{H}_{2} \mathrm{O}$, and the total metal loading was $8 \mathrm{wt} \%$. The $\mathrm{Au} / \mathrm{Ag}$ molar ratios discussed below are nominal values and are consistent with the analytical results from energy-dispersive X-ray spectrometry (EDXS) (see Supporting Information Table S1). In our synthesis, the surfactant $\mathrm{CTAB}$ acts both as a stabilizing agent for nanoparticles and subsequently as a template for assembling 

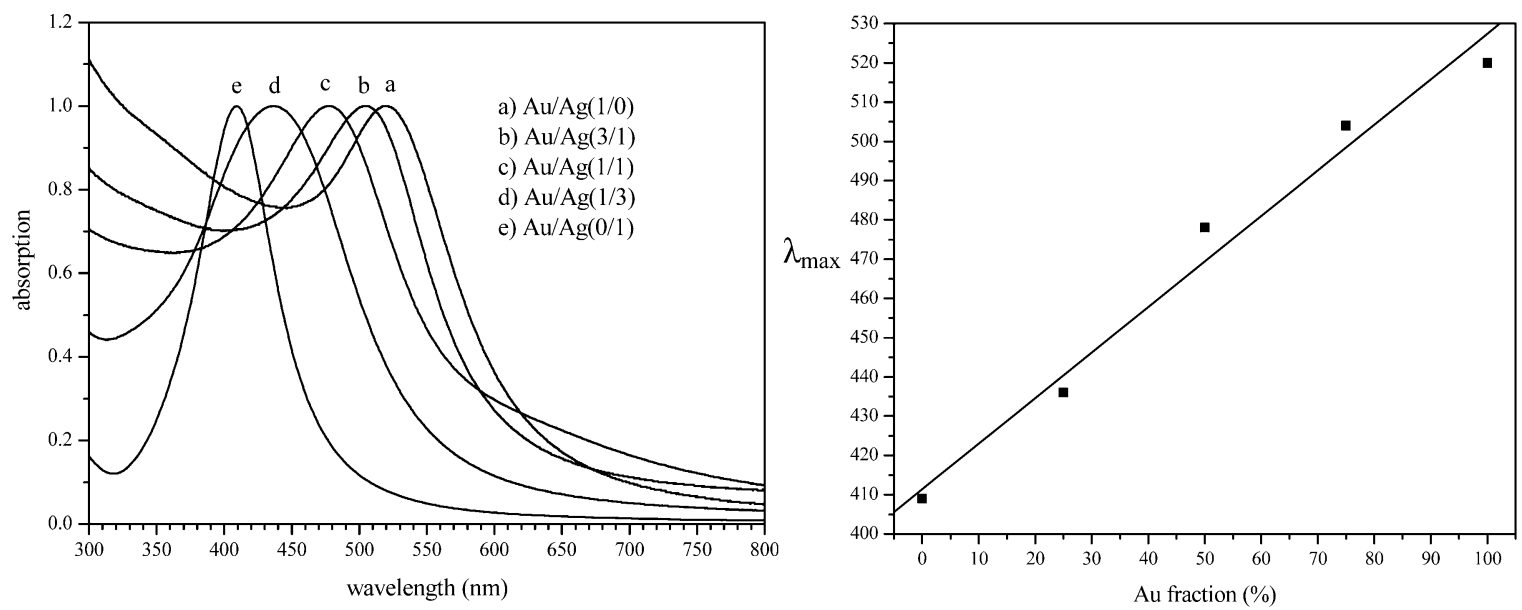

Figure 1. (left) UV-vis absorption spectra of gold, silver, and gold-silver alloy nanoparticles with varying Au/Ag molar ratios. The spectra have been normalized at the absorption maximum. (right) The absorption maximum of the plasmon resonance band versus the gold molar fraction.
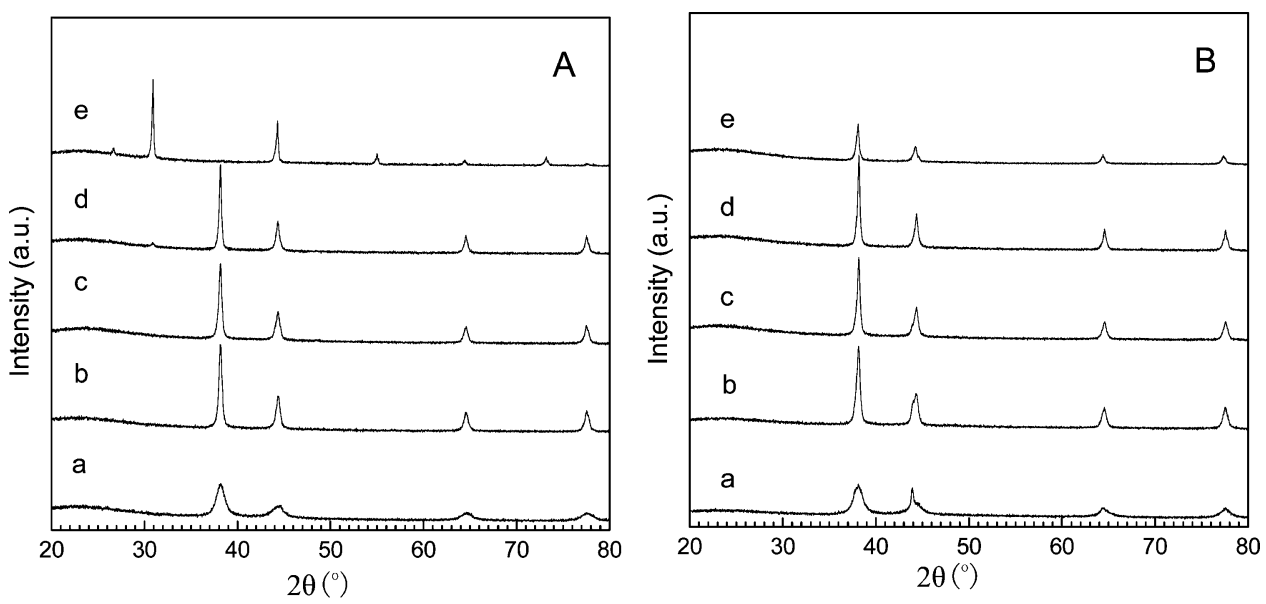

Figure 2. XRD patterns of catalysts with different $\mathrm{Au} / \mathrm{Ag}$ molar ratios (A) after calcination and then (B) reduction. Nominal compositions: (a) $\mathrm{Au} / \mathrm{Ag}=1 / 0 ;$ (b) $\mathrm{Au} / \mathrm{Ag}=5 / 1 ;(\mathrm{c}) \mathrm{Au} / \mathrm{Ag}=3 / 1 ;$ (d) $\mathrm{Au} / \mathrm{Ag}=1 / 1 ;$ (e) $\mathrm{Au} / \mathrm{Ag}=0 / 1$.

mesoporous structure. Ultraviolet-visible (UV-vis) spectra (Figure 1) of the colloid solution show that there is only one absorption band for all the investigated samples and the absorption band is blue-shifted with decreasing $\mathrm{Au} / \mathrm{Ag}$ ratio. Furthermore, the maximum absorption bands follow a linear relationship with the molar fraction of gold. This is an indication of the formation of $\mathrm{Au}-\mathrm{Ag}$ alloy nanoparticles. ${ }^{11}$ Transmission electron microscopy (TEM) images of the colloid (Supporting Information Figure 1S) show that both monometallic and bimetallic nanoparticles possess an average size of $<10 \mathrm{~nm}$. However, as we will discuss later, after incorporation of the nanoparticles into the mesoporous support and subjecting it to hydrothermal and calcination treatments, the surface composition and particle size distribution change (see the Supporting Information). The molar ratios of gold to silver discussed in the text are nominal values, which may be very different from the real $\mathrm{Au} / \mathrm{Ag}$ ratios on the surface of the catalysts. Analytical results by EDXS and X-ray photoelectron spectoscopy (XPS) are given in Supporting Information Table S1. The Au/Ag ratios determined by EDXS are consistent with the nominal values. However, the XPS results show that, after calcinations and reduction, the catalyst surface is enriched with $\mathrm{Ag}$.

Using the $\mathrm{CTAB}$ protected $\mathrm{Au}-\mathrm{Ag}$ nanoparticle as the templating agent, we directly synthesized MCM-41. The lowangle X-ray diffraction (XRD) pattern shows a disordered MCM-41 structure (figure not shown here). Figure 2 shows the wide-angle XRD patterns of catalysts with different $\mathrm{Au} / \mathrm{Ag}$ molar ratios after calcination in air at $833 \mathrm{~K}$ and then reduction with $10 \% \mathrm{H}_{2} / \mathrm{N}_{2}$ at $873 \mathrm{~K}$. From Figure $2 \mathrm{~A}$, it is clear that all the $\mathrm{Au}-\mathrm{Ag}$ bimetallic catalysts have the same XRD patterns with monometallic Au@MCM catalyst, since gold and silver have almost the same lattice constant $(0.408 \mathrm{~nm}$ versus 0.409 $\mathrm{nm})$. In contrast, the Ag@MCM catalyst after calcination shows the XRD pattern of $\mathrm{AgBr}$, indicating that an $\mathrm{AgBr}$ phase is formed from the combination of $\mathrm{Ag}$ species and $\mathrm{Br}$ species from the decomposition product of CTAB during calcination. However, after chemical reduction, all the catalysts have the same XRD patterns, indicating that $\mathrm{Br}$ was completely removed and the $\mathrm{Au}-\mathrm{Ag}$ alloy was the only detected species by XRD. In fact, this result was further confirmed by the XPS and UV-vis investigations of the reduced samples (Supporting Information Table S2 and Figure S2). It is worth noting that, after calcination, the $\mathrm{Au}-\mathrm{Ag}$ metal particle size became larger compared with monometallic Au@MCM, as indicated by the sharper peaks in the XRD patterns. This can be further confirmed by the TEM investigations. As shown in Figure 3, the Au nanoparticles in $\mathrm{Au} @ \mathrm{MCM}$ have an average size of $\sim 6.7 \mathrm{~nm}$, whereas, for the $\mathrm{Au}-\mathrm{Ag}$ alloy catalysts, the average metal particle size is more than $30 \mathrm{~nm}$. Moreover, with an increase of Ag concentration, the particle size gets bigger. For the alloy catalyst with a Au/ $\mathrm{Ag}$ molar ratio of $3 / 1$, the average particle size is $\sim 33 \mathrm{~nm}$. When the $\mathrm{Au} / \mathrm{Ag}$ ratio is $1 / 1$, the average particle size increases to 52 $\mathrm{nm}$. The fact that the particle size is relatively big for all the catalysts containing Ag (Supporting Information Table S1) suggests that aggregation occurred during the calcination process, and the presence of Ag makes the aggregation more 

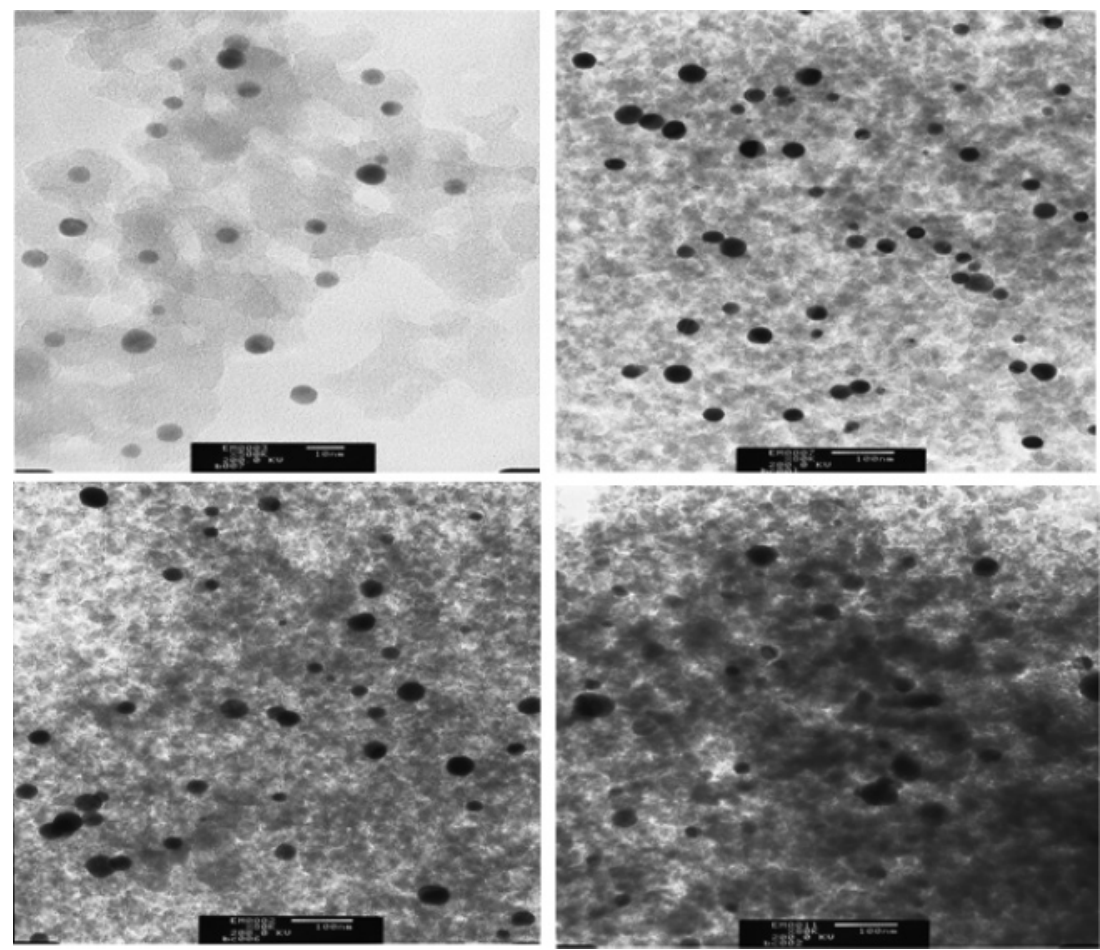

Figure 3. TEM images of catalysts with different $\mathrm{Au} / \mathrm{Ag}$ molar ratios. (top left) $\mathrm{Au} / \mathrm{Ag}=1 / 0$, scale bar $10 \mathrm{~nm}$; (top right) $\mathrm{Au} / \mathrm{Ag}=5 / 1$, scale bar $100 \mathrm{~nm}$; (bottom left) $\mathrm{Au} / \mathrm{Ag}=3 / 1$, scale bar $100 \mathrm{~nm}$; (bottom right) $\mathrm{Au} / \mathrm{Ag}=1 / 1$, scale bar $100 \mathrm{~nm}$.
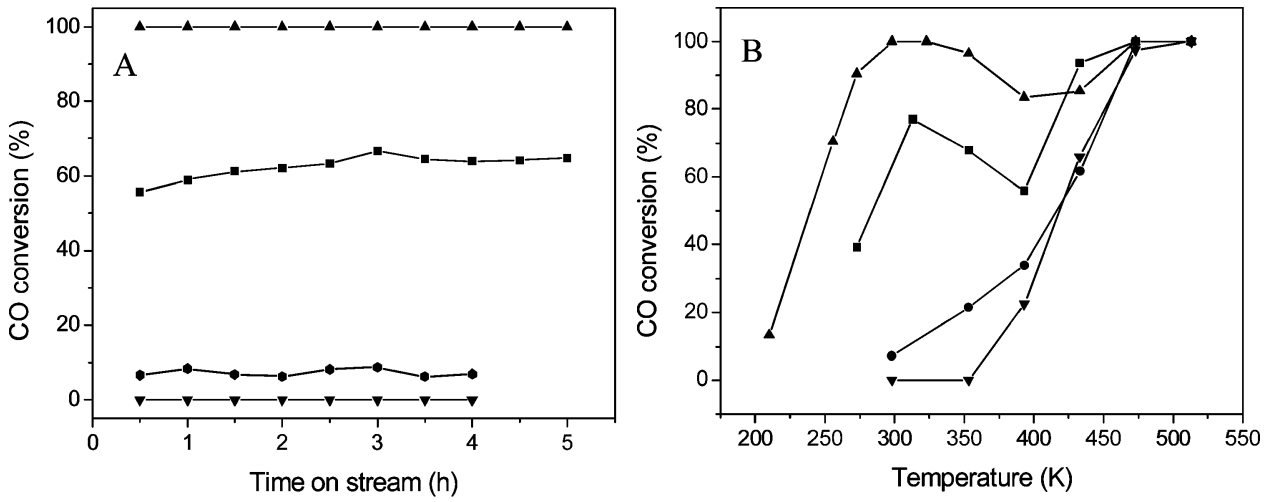

Figure 4. $\mathrm{CO}$ conversions (A) with time on stream at $298 \mathrm{~K}$ and $(\mathrm{B})$ versus reaction temperature: $(\mathbf{\Lambda}) \mathrm{Au} / \mathrm{Ag}=3 / 1 ;(\mathbf{\square}) \mathrm{Au} / \mathrm{Ag}=1 / 1 ;(\bullet) \mathrm{Au} / \mathrm{Ag}$ $=1 / 0 ;(\boldsymbol{\nabla}) \mathrm{Au} / \mathrm{Ag}=0 / 1)$.

severe. This is consistent with the XRD results and may be ascribed to the lower melting point of Ag. Moreover, a further careful examination with high-resolution TEM (HRTEM) revealed that there are very few small nanoparticles below 5 nm. Figure 3 also shows that the mesoporous silica particles are very disordered, having a domain size around $50 \mathrm{~nm}$ with a large fraction of textural porosity.

To examine the catalytic reactions, all the catalysts were activated at $873 \mathrm{~K}$ for $1 \mathrm{~h}$ under $10 \% \mathrm{H}_{2} / \mathrm{N}_{2}$ flow prior to testing. For the $\mathrm{CO}$ oxidation reaction, a feed gas of $1 \% \mathrm{CO}$ in air passed through a $0.04 \mathrm{~g}$ catalyst bed with a total flow rate of 66.7 $\mathrm{mL} / \mathrm{min}$, corresponding to a space velocity of $1.0 \times 10^{5}$ $\mathrm{mL} \cdot \mathrm{g}_{\text {cat. }}{ }^{-1} \cdot \mathrm{h}^{-1}$. The reactant gases were purified by a $4 \AA$ molecular sieve and then mixed and flowed into the reactor for the reaction. Thus, the water vapor content in the reactant stream is no more than $4 \mathrm{ppm}$. Figure 4 shows the $\mathrm{CO}$ conversions over Au-Ag@MCM with various compositions. One can see that at 298 K the pure silver catalyst Ag@MCM did not exhibit any catalytic activity, while the Au@MCM catalyst only had a low $\mathrm{CO}$ conversion of $\sim 7 \%$. The low activity of Au@MCM is related to the inert nature of the aluminosilicate support. ${ }^{12}$ In contrast, the $\mathrm{Au}-\mathrm{Ag}$ alloy catalyst manifests a strongly synergistic effect in $\mathrm{CO}$ oxidation. When the $\mathrm{Au} / \mathrm{Ag}$ ratio is $3 / 1,5 / 1$, or $10 / 1$, CO was completely converted at ambient temperature (for clarity, the latter two catalysts were not shown in the figure to avoid overcrowding). Even at a temperature as low as $250 \mathrm{~K}$, the $\mathrm{Au}-\mathrm{Ag}$ alloy catalysts were active. The reaction rate of $8.7 \times 10^{-6} \mathrm{~mol} \cdot \mathrm{g}_{\mathrm{cat}}{ }^{-1} \cdot \mathrm{s}^{-1}$ over $\mathrm{Au}-\mathrm{Ag} @ \mathrm{MCM}$ with a $\mathrm{Au} / \mathrm{Ag}$ ratio of $3 / 1$ is comparable to the reported best active catalysts, such as $\mathrm{Au} / \mathrm{TiO}_{2}{ }^{13}$ and $\mathrm{Au} / \mathrm{Fe}_{2} \mathrm{O}_{3} .{ }^{14}$ This is rather surprising considering that aluminosilicates are traditionally considered as an inactive support for $\mathrm{Au}$ catalysts. It is the alloying of silver with gold that dramatically increases the catalytic activity. When the $\mathrm{Au} / \mathrm{Ag}$ ratio is increased to $5 / 1$ and $10 / 1$, the reaction rate at $250 \mathrm{~K}$ is slightly lower than that on a catalyst with a $\mathrm{Au} / \mathrm{Ag}$ ratio of 3/1. It is worth noticing that, in contrast to the monometallic $\mathrm{Au}$ or $\mathrm{Ag}$ catalyst, all the $\mathrm{Au}-\mathrm{Ag}$ alloy catalysts show an activity dip with the reaction temperature between 353 and $433 \mathrm{~K}$. Such non-monotonic temperature dependence may imply two different mechanisms of the catalysis of $\mathrm{CO}$ oxidation. We believe the catalysis behavior above $400 \mathrm{~K}$ is similar to that of pure gold, while low- 
temperature catalysis is helped by the alloying of Ag with Au. It merits further detailed studies.

Furthermore, the size of the $\mathrm{Au}-\mathrm{Ag}$ nanoparticles does not seem to be a very critical factor. It is well-known that only very small gold nanoparticles $(\sim 3 \mathrm{~nm})$ can manifest high catalytic activity for $\mathrm{CO}$ oxidation at low temperatures. However, in the present work, by alloying $\mathrm{Au}$ with $\mathrm{Ag}$, the $\mathrm{Au}-\mathrm{Ag}$ bimetallic nanoparticles with a big size of $\sim 30 \mathrm{~nm}$ exhibited extraordinarily high activity. More importantly, such a high activity was obtained on a traditionally inert support. Although the underlying mechanism of catalysis by this alloy system is not clear, we believe that Ag plays a key role in the activation of oxygen, and most likely, the $\mathrm{CO}$ oxidation reaction occurred on the neighboring sites above $\mathrm{Au}$ and $\mathrm{Ag}$ atoms. It is the cooperation effect of $\mathrm{Au}$ and $\mathrm{Ag}$ that is important, and the size of the $\mathrm{Au}-$ Ag nanoparticles does not seem to play a critical role as in the case of Au nanoparticles. Previously, Iizuka et al. did find that silver-impurity-containing Au powder gave catalytic activities quite independent of particle sizes. ${ }^{9}$

In this work, our direct synthesis of $\mathrm{Au}-\mathrm{Ag} @ \mathrm{MCM}$ allowed us to use the well-developed solution synthesis of alloy $\mathrm{Au}-$ Ag nanoparticles. However, the control of the particle size is not very good because of the extensive sintering in calcinations. The calcinations and reduction treatments are necessary for the catalytic activity. An alternative approach is to use wellstructured and surface-functionalized MCM-41 to adsorb Au sources and do the chemical reduction inside the channel. ${ }^{15-17}$ However, although successful for loading monometallic nanoparticles, it would be difficult for this approach to be adapted to the formation of alloy.

In summary, we have developed a highly efficient catalyst system for $\mathrm{CO}$ oxidation with $\mathrm{Au}-\mathrm{Ag}$ alloy nanoparticles supported on the mesoporous aluminosilicate MCM-41. The alloying of $\mathrm{Au}$ and $\mathrm{Ag}$ shows a strong synergistic effect in promoting the low-temperature oxidation of $\mathrm{CO}$. In the catalysis, the size effect is no longer the critical factor. Synergistic effects of nanocatalysts through bimetallic alloying may be exploited on other catalyst systems for other reactions.
Acknowledgment. This work was supported by a grant from the Ministry of Education of Taiwan through Academy Excellent program. We thank Prof. B. Z. Wan for help in experiments and discussions.

Supporting Information Available: Textual properties, UV-vis spectra, and XPS results of the reduced $\mathrm{Au}-$ $\mathrm{Ag} @ \mathrm{MCM}$ catalysts as well as TEM images of $\mathrm{Au}-\mathrm{Ag}$ alloy colloid and size distribution. This material is available free of charge via the Internet at http://pubs.acs.org.

\section{References and Notes}

(1) Haruta, M. Chem. Rec. 2003, 3, 75. 319.

(2) Bond, G. C.; Thompson D. T. Catal. Rev.-Sci. Eng. 1999, 41,

(3) Schubert, M. M.; Hackenberg, S.; van Veen, A. C.; Muhler, M.; Plazak, V.; Behm, R. J. J. Catal. 2001, 197, 113.

(4) Liu, H.; Kozlov, A. I.; Kozlova, A. P.; Shido, T.; Asakura, K.; Iwasawa, Y. J. Catal. 1999, 185, 252.

(5) Liu, Z.-P.; Hu, P.; Alavi, A. J. Am. Chem. Soc. 2002, 124, 14770.

(6) Haruta, M. Catal. Today 1997, 36, 153.

(7) Häkkinen, H.; Abbet, S.; Sanchez, A.; Heiz, U.; Landman, U. Angew. Chem., Int. Ed. 2003, 42, 1297.

(8) Venezia, A. M.; Liotta, L. F.; Pantaleo, G.; La Parola, V.; Deganello, G.; Beck, A.; Koppany, Zs.; Frey, K.; Horvath, D.; Guczi, L. Appl. Catal., A 2003, 251, 359 .

(9) Iizuka, Y.; Kawamoto, A.; Akita, K.; Date, M.; Tsubota, S.; Okumura, M.; Haruta, M. Catal. Lett. 2004, 97, 203.

(10) (a) Lin, H. P.; Chi, Y. S.; Lin, J. N.; Mou, C. Y.; Wan, B. Z. Chem. Lett. 2001, 30, 1116. (b) Chi, Y. S.; Lin, H. P.; Lin, J. N.; Mou, C. Y.; Wan, B. Z. In Nanoporous Materials III; Sayari, A., Jaroniec, M., Eds.; Elsevier Scientific Publishers B. V.: Amsterdam, The Netherlands, 2002; p 329.

(11) Chen, D. H.; Chen, C. J. Mater. Chem. 2002, 12, 1557.

(12) Okumura, M.; Tsubota, S.; Iwamoto, M.; Haruta, M. Chem. Lett. 1998, $27,315$.

(13) Bamwenda, G. R.; Tsubota, S.; Nakamura, T.; Haruta, M. Catal. Lett. 1997, 44, 83.

(14) Kozlov, A. I.; Kozlova, A. P.; Asakura, K.; Matsui, Y.; Kogure, T.; Shido, T.; Iwasawa, Y. J. Catal. 2000, 196, 56.

(15) Overbury, S. H.; Ortiz-Soto, L.; Zhu, H. G.; Lee, B. W.; Amiridis, M. D.; Dai, S. Catal. Lett. 2004, 95, 99.

(16) Yang, C. M.; Kalwei, M.; Schüth, F.; Chao, K. J. Appl. Catal., A 2003, 254, 289.

(17) Chi, Y. S.; Lin, H. P.; Mou, C. Y. Appl. Catal., A, submitted for publication. 